Hydrol. Earth Syst. Sci. Discuss., 3, 3321-3332, 2006 www.hydrol-earth-syst-sci-discuss.net/3/3321/2006/

(C) Author(s) 2006. This work is licensed under a Creative Commons License.
Hydrology and

Earth System

Sciences

Discussions

Papers published in Hydrology and Earth System Sciences Discussions are under open-access review for the journal Hydrology and Earth System Sciences

\title{
The Hydrologic Ensemble Prediction EXperiment (HEPEX)
}

\section{J. Schaake ${ }^{1}$, K. Franz ${ }^{2}$, A. Bradley ${ }^{3}$, and R. Buizza ${ }^{4}$}

${ }^{1}$ National Oceanic and Atmospheric Administration/National Weather Service, Consultant, Silver Spring, MD, USA

${ }^{2}$ Iowa State University, Geological and Atmospheric Sciences, Ames, IA, USA

${ }^{3}$ The University of lowa, lowa Institute of Hydraulic Research - Hydroscience and Engineering, lowa City, IA, USA

${ }^{4}$ European Center for Medium-Range Weather Forecasts, Reading, UK

Received: 12 June 2006 - Accepted: 27 July 2006 - Published: 31 October 2006

Correspondence to: J. Schaake (john.schaake@noaa.gov)

\section{HESSD}

3, 3321-3332, 2006

The Hydrologic Ensemble Prediction EXperiment (HEPEX)

J. Schaake et al.

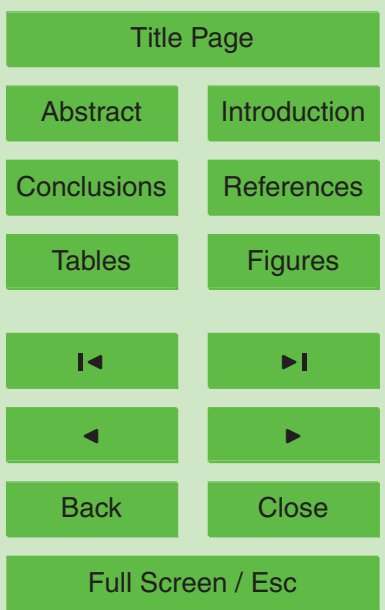

Printer-friendly Version

Interactive Discussion 


\section{Abstract}

Users of hydrologic predictions need reliable, quantitative forecast information, including estimates of uncertainty, for lead times ranging from less than an hour during flash flooding events to more than a year for long-term water management. To meet this 5 need, operational agencies are developing hydrological ensemble forecast techniques to account for sources of uncertainty such as future precipitation, initial hydrological conditions, and hydrological model limitations including uncertain model parameters. Research advances in areas such as hydrologic modeling, data assimilation, ensemble prediction, and forecast verification need to be incorporated into operational forecasting systems to assure that the state-of-the-art products are reaching the forecast user community. The Hydrologic Ensemble Prediction EXperiment (HEPEX) has been formed to develop and demonstrate new hydrologic forecasting technologies, and to facilitate the implementation of beneficial technologies into the operational environment.

\section{Objective}

15 Development of reliable, skillful hydrologic ensemble forecast procedures is a major undertaking that requires global and multidisciplinary collaborations. The Hydrologic Ensemble Prediction EXperiment (HEPEX) (http://hydis8.eng.uci.edu/hepex/) is an international effort that brings together hydrological and meteorological communities to develop advanced probabilistic hydrologic forecast techniques that use emerging (http://www.gewex.org/). The HEPEX mission is to demonstrate how to produce reliable hydrological ensemble predictions that can be used with confidence by emergency management and water resources sectors to make decisions that have important consequences for the economy, environment, public health and safety.

HESSD

3, 3321-3332, 2006

The Hydrologic Ensemble Prediction EXperiment (HEPEX)

J. Schaake et al.

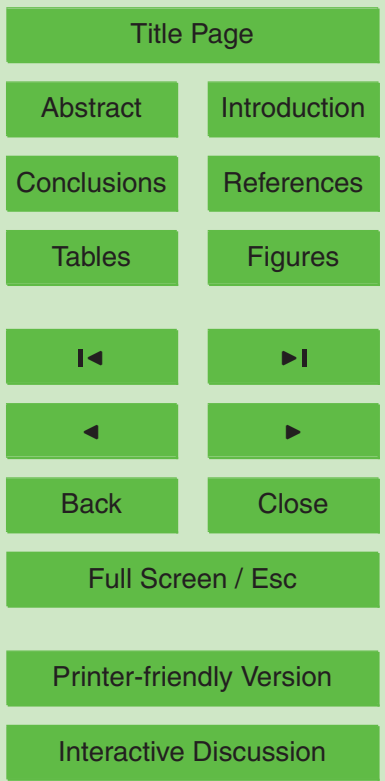

EGU 


\section{Affiliations and participation}

HEPEX is a global project affiliated with GEWEX to help GEWEX meet its water resource applications objectives. Also, it is an important GEWEX contribution to the overarching WCRP Coordinated Observation and Prediction of the Earth System (COPES) 5 initiative (http://copes.ipsl.jussieu.fr/). HEPEX expects that the IAHS Predictions for Ungaged Basins (PUB) initiative (http://cee.uiuc.edu/research/pub/) will contribute both new science and data sets, and will participate in some of the test bed projects. Ensemble atmospheric forecasts are expected to be available for HEPEX applications from a number of models participating in the World Weather Research Project's THORPEX Interactive Grand Global Ensemble Experiment (TIGGE) (WMO, 2005). Brief descriptions of HEPEX were recently published in EOS (Franz et al., 2005) and in the GEWEX Newsletter (Schaake et al., 2005).

Participation in HEPEX is open to anyone wishing to contribute to its objectives. HEPEX activities will include test bed projects, development of supporting data sets, development of components of a Community Hydrologic Prediction System (CHPS), and sponsorship of workshops and special sessions at scientific meetings.

HEPEX invites potential forecast users to participate in HEPEX activities and the "Users Forum". The "Users Forum" helps oversee activities to assure user needs are being addressed. Users have been active participants in workshops and are involved in various HEPEX projects.

The first international HEPEX workshop was held 8-10 March 2004, hosted by the European Center for Medium-Range Weather Forecasts (ECMWF). This workshop initiated HEPEX and established its science agenda. The second workshop was held 19-21 July 2005 at the National Center for Atmospheric Research (NCAR) and iniHEPEX web site (http://hydis8.eng.uci.edu/hepex/).

HESSD

3, 3321-3332, 2006

The Hydrologic Ensemble Prediction EXperiment (HEPEX)

J. Schaake et al.

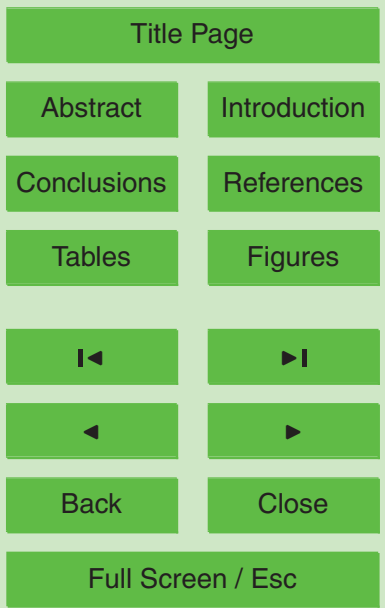

Printer-friendly Version

Interactive Discussion 


\section{Science questions}

The key science issue for HEPEX is reliable quantification of hydrologic forecast uncertainty. HEPEX plans to address the following key questions:

- What are the adaptations required for meteorological ensemble systems to be coupled with hydrological ensemble systems?

- How should the existing hydrological prediction systems be modified to account for all sources of uncertainty within a forecast?

- What is the best way for the user community to take advantage of ensemble forecasts?

\section{Hydrologic Ensemble Prediction Systems}

Two key goals of HEPEX are to develop and test the main components of a hydrologic prediction system (Fig. 1) and to combine these components to form the Community Hydrologic Prediction System. The purpose of CHPS is to greatly accelerate the infusion of new hydrologic science into hydrologic forecast operations. To accomplish this, CHPS is expected to be designed using an open system architecture that can easily accommodate the addition of new models and procedures into any one of the forecast system components. CHPS is expected to be both a testing ground for new forecasting technology and a pathway for integration of that technology into operations.

\section{Test bed projects}

20 A HEPEX Test Bed is a setting for HEPEX-community experiments. A test bed could be a single basin (and its subbasins), a region containing multiple basins, or possibly a global collection of basins that facilitate experiments addressing questions over a range

The Hydrologic Ensemble Prediction EXperiment (HEPEX)

J. Schaake et al.

Title Page

Abstract Introduction

Conclusions References

Tables Figures

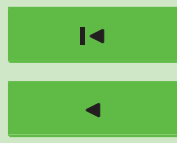
$\rightarrow 1$

Back

Close

Full Screen / Esc

Printer-friendly Version

Interactive Discussion 
of scales and climates. Regardless of geographical domain, test beds focus on one or more clearly defined HEPEX science questions; have the potential to develop data resources needed to address the questions of the HEPEX community experiments; and are expected to include active user participation. In addition, the test bed projects 5 are needed to provide a framework for development of CHPS and to meet the HEPEX demonstration goal. Proposals for eight test bed projects were presented at the second HEPEX workshop. The proposed test beds are outlined in Table 1; and their global locations are illustrated in Fig. 2.

\section{Application of weather and climate forecasts}

10 One of the main links between GEWEX and HEPEX is that HEPEX hopes to demonstrate how to use improved climate forecast products that GEWEX will help to produce. This includes developing a seamless approach to the application of weather and climate forecasts through collaboration with the THORPEX Interactive Grand Global Ensemble project (TIGGE). TIGGE is "a project designed to develop, demonstrate and 15 evaluate a multi-model, multi-analysis and multi-national ensemble prediction system" for short- to medium-range weather prediction (WMO, 2005). TIGGE is expected to provide an ensemble of two-week meteorological forecast inputs that can be used for hydrologic ensemble prediction experimentation by HEPEX.

Biases in weather and climate forecasts must be removed and the forecasts must

be downscaled for hydrologic application. This requires an archive of forecasts and corresponding observations that can be used to estimate parameters of the hydrologic ensemble preprocessor. An important initial global source of meteorological ensemble forecasts is the archive of ensemble forecasts from the fixed version of the NWS Global Forecast System (GFS) for the period 1979 to the present (http://www.cdc.noaa. available daily. A measure of the potential importance of the ensemble precipitation forecasts is the correlation between the ensemble mean and the corresponding obser-

\section{HESSD}

3, 3321-3332, 2006

The Hydrologic Ensemble Prediction EXperiment (HEPEX)

J. Schaake et al.

Title Page



Introduction

Conclusions

Tables

References

Figures

14

$-1$

4

Back

Close

Printer-friendly Version

Interactive Discussion

EGU 
vation. The high correlation for 7- and 14-day total precipitation for most of the U.S., and the eastern/mid-western US and the mountain west in particular, demonstrates their potential for improving hydrological predictions (see Fig. 3).

\section{Hydrologic uncertainty and data assimilation}

5 There are many sources of hydrologic uncertainty; one of the most important is the uncertainty in initial conditions. Basin initial conditions are often difficult to identify for various reasons including a lack of reliable observations or the inability to directly relate model states to field observations. Therefore, for hydrologic ensemble prediction, an ensemble of initial conditions may be needed to effectively assess the impact on predictions. Most current data assimilation techniques aim to produce an optimal estimate in initial conditions and an estimate of uncertainty - but not ensemble members. Enhanced techniques that produce an ensemble of initial conditions and are also appropriate for operational forecasting are needed.

Other sources of uncertainty derive from model limitations, including model structure and corresponding estimates of parameter values. Representing this has been an important topic for the PUB initiative and for the international MOPEX project (http: //www.seas.ucla.edu/ thogue/MOPEX/).

\section{Operational application}

The final acid tests for HEPEX will be whether the resulting prediction system(s) can

be used in an operational forecast environment and the subsequent forecast products are beneficial to users and decision makers. It is highly unlikely that totally automated hydrologic ensemble prediction systems that ingest observations and weather and climate forecasts can be created to produce consistently reliable hydrologic ensemble forecasts without human forecaster involvement. Therefore the appropriate roles for
HESSD

3, 3321-3332, 2006

The Hydrologic Ensemble Prediction EXperiment (HEPEX)

J. Schaake et al.

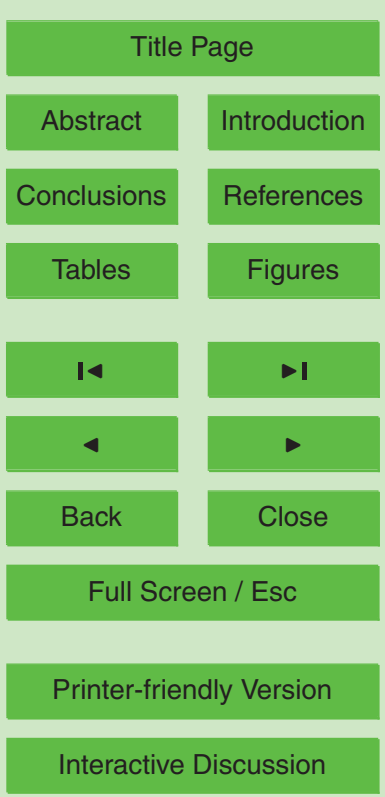

EGU 
human involvement must be found and demonstrated in an operational environment as well. Feedback from the user community will serve as the final verdict regarding the success of HEPEX, as the HEPEX goal emphasizes providing benefits to "emergency management and water resources sectors".

\section{HESSD}

3, 3321-3332, 2006

\section{The Hydrologic Ensemble Prediction EXperiment (HEPEX)}

Franz, K., Ajami, N., Schaake, J., and Buizza, R.: Hydrologic Ensemble Prediction Experiment Focuses on Reliable Forecasts, Eos, 86(25), 239, 21 June 2005.

Schaake, J., Franz, K., Bradley, A., and Buizza, R.: Hydrologic Ensemble Prediction Experiment, GEPEX Newsletter, 15(4), 10, November, 2005.

10 WMO: First Workshop on the THORPEX Interactive Grand Global Ensemble (TIGGE), Final Report, WMO/TD-No. 1273, WWRP/THORPEX No.5, 1995.

J. Schaake et al.

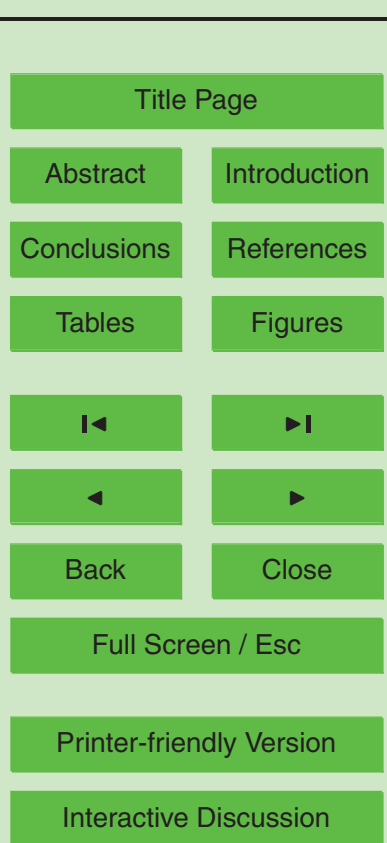


Table 1. Test Bed Projects.

HESSD

\begin{tabular}{l} 
Project \\
\hline Great Lakes, \\
Canada/US \\
Bangladesh \\
Santa Fe Basin, \\
Brazil
\end{tabular}

Objectives

Contact

Demonstrate the importance of relatively detailed atmospheric and hydrologic modeling for mediumrange atmospheric and hydrologic forecasting on large basins.

V. Fortin

vincent.fortin@ec.gc.ca

Provide operational real-time forecasts of river dis- Tom Hopson

charge into Bangladesh at daily, weekly, monthly, and Thomas.Hopson@Colorado.EDU seasonal time-scales.

\section{Tucci}

tucci@iph.ufrgs.br

1. Explore the use of ensembles produced by the CPTEC model of global climate.

2. Explore the use of forecasts produced by RAMS for lead-times extending up to a month and longer.

3. Explore the use of short-term rainfall forecasts from the operational ETA model of CPTEC.

Po Basin, Italy

1. Test simplistic routines for bias removal in an area such as Northern Italy that is dominated by important orography (Alps).

2. Test methods for flood forecasting based on threshold exceedances.

Western Basins, Develop hydrologic ensemble forecasting techniques U.S./B.C.,

Canada that are particular to the orographically complex, snowmelt-driven basins of the Western US and British Columbia. Focus on monthly to seasonal lead times.

J. Thielen

jutta.thielen@jrc.it

F. Weber

Frank.Weber@bchydro.bc.ca

A. Wood

aww@hydro.washington.edu

K. Werner

Kevin.Werner@noaa.gov

3, 3321-3332, 2006

\section{The Hydrologic Ensemble Prediction EXperiment (HEPEX)}

J. Schaake et al.

Title Page

Abstract

Introduction

Conclusions

References

Tables

Figures

14

4

Back

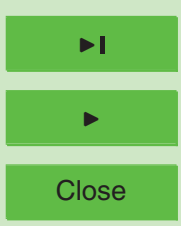

Full Screen / Esc

Printer-friendly Version

Interactive Discussion 
Table 1. Continued

\section{HESSD}

\begin{tabular}{lc}
\hline Project & Objectives \\
\hline Southeast & Address the following HEPEX science questions: \\
Basins, U.S. & 1. How do we generate skillful and reliable mete- \\
& orological forcing for seasonal hydrologic fore- \\
casting? & 2. How do we generate the hydrologic ensembles \\
& that reflect the total uncertainties? \\
3. How can climate information, such as climate \\
model forecasts or teleconnections, be used re- \\
liably in seasonal hydrologic forecasting?
\end{tabular}

4. How do we validate hydrologic ensembles for extreme events?

Statistical Downscaling

Hydrologic Uncertainty

1. Identify the space-time scales for which forecast skill is present for different variables and develop methods to extract and combine information at different space-time scales

2. Identify the GFS output variables that can be used to provide sub-grid information that can be used in a statistical model to replicate precipitation processes.

3. Identify the sample size required to reliably forecast precipitation, temperature, and streamflow, for different thresholds.

Hydrologic uncertainty can be described in terms of uncertainties in model inputs, model parameters, and

\section{Contact}

\section{Eric Wood}

efwood@princeton.edu

3, 3321-3332, 2006

\section{The Hydrologic Ensemble Prediction EXperiment (HEPEX)}

J. Schaake et al.

Title Page

\section{Clark}

clark@vorticity.colorado.edu model structure; leading to uncertainties in model states and fluxes. What are the advantages and limitations of different methods for characterizing and reducing this uncertainty in hydrologic model simulaJ. Schaake john.schaake@noaa.gov tions?
M. Clark

clark@vorticity.colorado.edu

J. Vrugt

vrugt@lanl.gov
Introduction

Abstract

References

Conclusions

\section{Figures}

Tables

14

$>$ I

4

Back

Close

Full Screen / Esc

Printer-friendly Version

Interactive Discussion 


\section{HESSD}

3, 3321-3332, 2006

Elements of a Hydrologic Ensemble Prediction System

The Hydrologic Ensemble Prediction EXperiment (HEPEX)

J. Schaake et al.

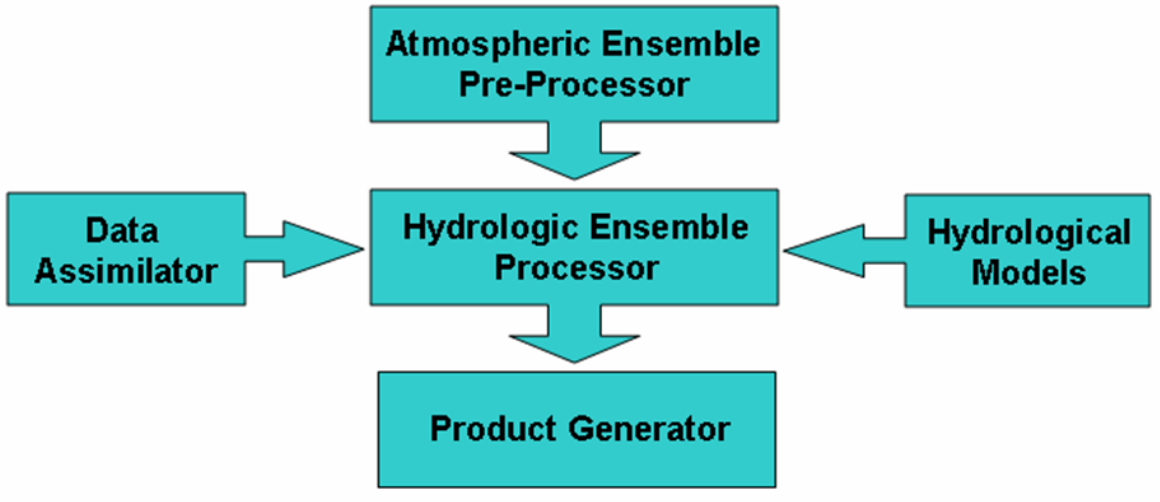

HEPEX

Fig. 1. Components of a hydrologic prediction system.



Full Screen / Esc

Printer-friendly Version

Interactive Discussion

EGU 


\section{HESSD}

3, 3321-3332, 2006

\section{The Hydrologic Ensemble Prediction EXperiment (HEPEX)}

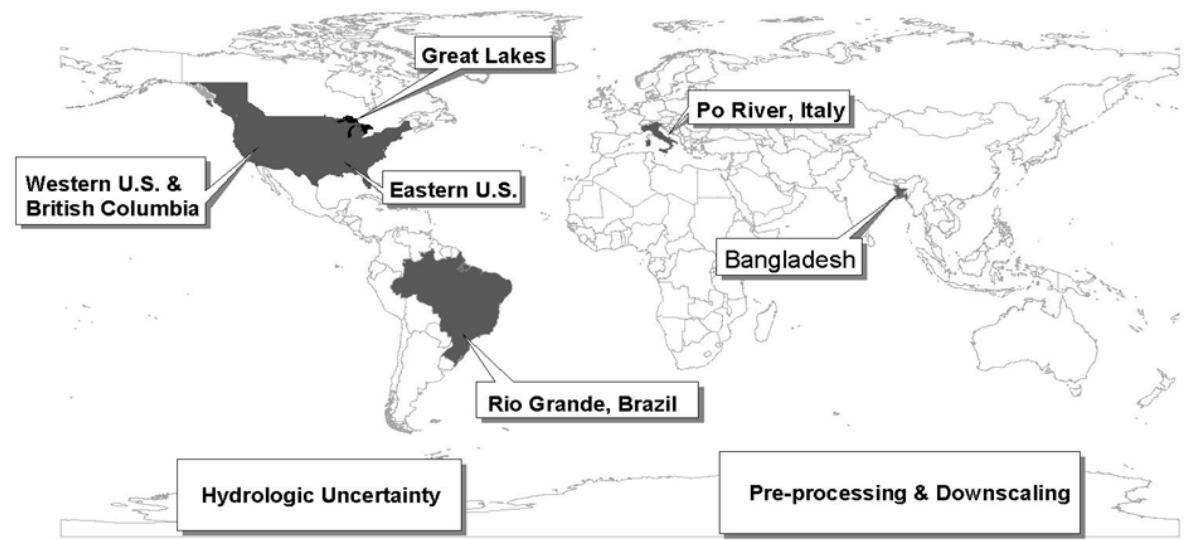

J. Schaake et al.

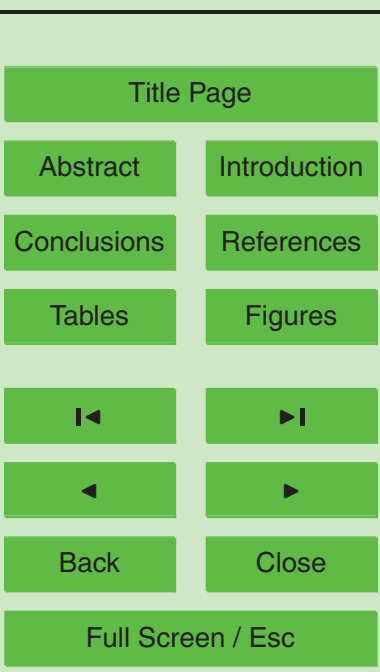

Printer-friendly Version

Interactive Discussion 


\section{HESSD}

Correlation coefficients for January

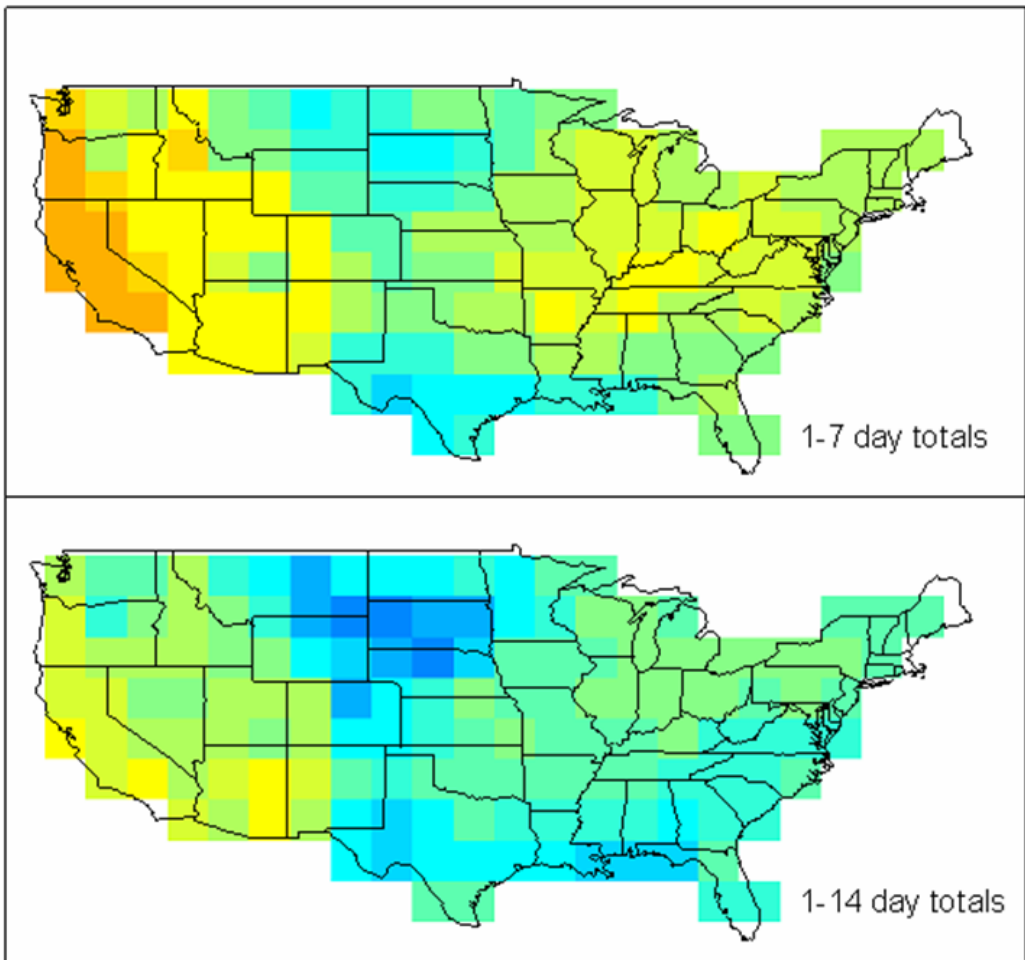

Fig. 3. Correlation coefficients between observed and forecasted precipitation across the U.S. for January.
3, 3321-3332, 2006

The Hydrologic Ensemble Prediction EXperiment (HEPEX)

J. Schaake et al.

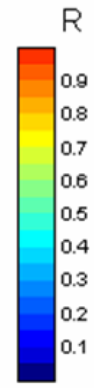

Title Page

Abstract

Introduction

Conclusions

References

Tables

Figures

14

4

Back

Close

\section{Full Screen / Esc}

Printer-friendly Version

Interactive Discussion

EGU 